were hypertensive ( $>96 \mathrm{~mm} \mathrm{Hg}$ ). Of these, $447981(74.4 \%)$ had previously been detected, $36626(56.6 \%)$ were on therapy, and 25857 $(40.1 \%)$ were on therapy and controlled. Even if we set aside the possibility of natura attrition (levels of blood pressure and cholesterol are lower in the Tecumseh population study) and the contribution of North American enthusiasms for jogging, dieting, and stopping smoking, it is difficult to escape the conclusion that programmes of detection and control of high blood pressure are having a considerable effect here which is not yet apparent in the UK, and that the sooner more is done about it the better.

Our studies in general practice in Scotland ${ }^{6}$ have confirmed the fact that $85 \%$ of patients on NHS lists consult their family doctor over a three-year period. A nurse or trained medical secretary can take blood pressure and even repeat the observations after four weeks before troubling the busy doctor, and in so doing achieve as nearly $100 \%$ cover in five years as would not matter. As to time and effort, our doctor colleagues told us that it took only a minute or so to take blood pressure and it was not worth troubling the nurse or receptionist.

The Hypertension Detection and Follow-up Program $^{2}$ has just reported that the systematic effective management of hypertension has great potential for reducing mortality for the large number of people with high blood pressure in the population, including those with "mild" hypertension. The North Karelia Study ${ }^{8}$ has reported similarly. The outcome of the continuing UK trial of mild-tomoderate hypertension ${ }^{9}$ is awaited with special interest as being based on a population among whom the incidence of coronary heart disease is rising-as opposed to declining in the other two studies. What is needed now is a clarion call to more action and a deaf ear to doubt.

VICTOR M HAWTHORNE

Department of Epidemiology,

University of Michigan

Ann Arbor, Public Health,

USA

${ }^{1}$ Fejfar Z. In: Shaper AG, Hutt MSR, Fejfar Z, eds. Cardiovascular disease in the tropics. London: Cardiovascular disease in the tropics.
British Medical Association, 1974:1-6.

2 Hawthorne VM. Lancet 1978;i:1038.

3 World Health Organisation. World Health statistics annual, 1969, vol 1. Geneva: WHO, 1972.

annual, 1969, vol 1. Geneva: WHO, 1972.
+ World Health Organisation. World health statistics annual, 1973, vol 1. Geneva: WHO, 1976.

${ }^{6}$ Remington RD. Heart disease mortality is dropping what are we doing right? Atlanta, Georgia: Nationa Center for Health Statistics, 1978.

${ }^{6}$ Barber JH, Beevers DG, Fife R, et al. Br Med $\mathcal{f}$ $1979 ; \mathrm{i}: 843-6$

Hypertension Detection and Follow-up Program

Salonen IT, Puska P, Mustaniemi H. Br Med f 1979

ii:1178-83.

MRC Working Party on Mild-to-moderate Hypertension. Br Med f 1977;i:1437-40.

\section{Surgery in outpatients}

SIR,-The authors of your review article on day-stay surgery (8 December, p 1459) advocate studies of patients' reaction to this type of care. This wirk has already been undertaken, independently, by several groups of anaesthetists in this country. ${ }^{12}$ The results should temper excessive enthusiasm for shortstay care of patients having general anaesthesia. Roughly a quarter of my patients undergoing termination of pregnancy had either headache, drowsiness, or uterine colic the next day and half did not feel like returning to norma activities at that time. Similar results have been found by other workers, using different anaesthetic combinations, in dental patients and in minor gynaecological surgery. ${ }^{2}$ It is now my practice to offer patients overnight stay where the home circumstances are not suitable for early postoperative discharge.

Two groups of patients have been recom mended for day-stay surgery who particularly warrant overnight care. They are children undergoing tonsillectomy and patients having laparoscopy. ${ }^{3}$ The rapidity with which haemorrhage can kill a child after tonsillectomy mean that expert postoperative care is essential for a least the first 24 hours after operation. I have found that pelvic laparoscopy can give rise to referred diaphragmatic pain lasting for up to three days after operation, and frequently thi is distressing to the patient. Occasional patients request day-stay laparoscopy and I have never refused, on anaesthetic grounds, to allow them to go home. However, the likely pattern of recovery is always explained to the patient as part of my technique to minimise postoperative morbidity, ${ }^{4}$ and I have found that half of these patients requesting day stay actually remain in hospital overnight.

I believe that we should use our knowledge of patients' recovery patterns to provide the best care for them and their sojourn in hospital should be decided on this basis.

J Cundy

Lewisham Hospital

${ }^{1}$ Ogg TW. Br Med f 1972; ;iv:573-5.

owey RM, Stanford J, Ballard RM, Gilbert JR. $B r \mathcal{F}$ Anaesth 1979;51:453-5.

Thompson B, Wheeless CR. Obstet Gynaecol 1971; 38:912-5.

Engl f Med 1964;270:825-7.
Egert

\section{Indomethacin treatment of postural} hypotension in autonomic failure

SIR, - We would like to confirm and extend the interesting and important findings of Professor G Abate and others (8 December, p 1466) on the increased systemic vascular resistance produced by indomethacin in autonomic failure.

Indomethacin is not always successful in the treatment of postural hypotension ${ }^{1}$ and in an earlier paper that the authors refer to (reference 6) the diagnosis was not proved. ${ }^{1}$ They stated that their patients had idiopathic Parkinsonism; but all seven males (though admittedly elderly) were impotent, three patients had defective sweating, and eight had bladder dysfunction. The fall in mean blood pressure of $34.8 \mathrm{~mm} \mathrm{Hg}$ is greater than the blood pressure fall in patients with uncomplicated idiopathic Parkinsonism. ${ }^{2}$ All these findings suggest that some of their patients had autonomic failure and multiple system atrophy (Shy-Drager syndrome). Although classification may be difficult, it is important to observe ${ }^{3}$ the clinical, physiological, and biochemical criteria for differentiating between idiopathic Parkinsonism, idiopathic Parkinsonism with autonomic failure, and autonomic failure with multiple system atrophy. Professor Abate and his colleagues did not state the frequency, time, or duration of standing for blood pressure measurement. Patients with autonomic failure have such labile blood pressures that the precise conditions of measurement are important.

We are able to extend these observations (paper submitted for publication). In four patients with autonomic failure and multiple system atrophy, blood pressure was measured at 0600 and 1800 hours (times at which postural hypotension was greatest and least respectively) for seven days on no drugs and for seven days on indomethacin ( $25 \mathrm{mg}$ thrice daily for four days and $50 \mathrm{mg}$ subsequently). For the seven days before indomethacin, the average mean blood pressure in $\mathrm{mm} \mathrm{Hg}$ ( $\pm S D$ ) was: at 0600 hours-supine $92 \pm 11$, standing ( 5 minutes) $69 \pm 15$; and at 1800 hours-supine $102 \pm 16$, standing $76 \pm 17$. Indomethacin increased only the average mean supine pressure at 1800 hours $(139 \pm 23$, $\mathrm{p}=0.05$, paired $t$ test); other values did not change. The pressor sensitivity of our patients to intravenous noradrenaline and angiotensin II was increased by indomethacin. There were no detectable changes in blood volume.

Increased vasoconstriction caused by endogenous angiotensin II and noradrenaline from remaining nerve endings is probably one cause of the increase in systemic vascular resistance. Inhibition of prostaglandin synthesis may also be important for, in our patients, urinary prostaglandin excretion was greater than in normal subjects and was decreased by indomethacin. In cases of autonomic failure indomethacin may augment the beneficial effects of fludrocortisone, ${ }^{4}$ since both drugs can increase blood volume and vascular smooth muscle sensitivity to noradrenaline.

I BLEDDYN DAVIES ROGER BANNISTER Peter S SeVER

Medical Unit and Department of Neurology,

St Mary's Hospital Medical School,

London W2

1 Bannister R, Davies B, Sever P. Lancet 1978; : 1312. Gross $M$, Bannister $R$, Godwin-Austen $R$, Lancet 1972;i:174-6.

${ }^{3}$ Spokes EGS, Bannister R, Oppenheimer DR. $\mathcal{F}$ Neurol Sci 1979;43:59-82.

4 Perkins CM, Lee MR. Lancet 1978;ii:1058. ${ }^{4}$ Perkins CM, Lee MR. Lancet 1978;ii:1058.
Davies B, Bannister R, Sever P, Wilcox C. Br f Clin
Pharmacol 1979;8:253-60.

\section{Dietary fibre and blood pressure}

SIR,-The paper "Dietary fibre and blood pressure" by Angela Wright and others (15 December, p 1541) fails to consider a more important dietary control of blood pressurenamely, salt intake.

It is possible to question the role of sodium (and other cations) as was done in an editorial ${ }^{1}$ which confused the issue by discussing severe renal failure as well as essential hypertension and by not considering the normal person. There was already evidence ${ }^{2} 3$ showing the importance of sodium intake in animal blood pressure control, and a well-controlled clinical study $^{4}$ had clearly shown a mean decrease in blood pressure of $7 \cdot 7 / 4.4 \mathrm{~mm} \mathrm{Hg}$ with very modest salt restriction. This fall, of the same order as that now reported by the Southampton group, was similar to that found ${ }^{5}$ with an even less stringent sodium restriction (to a mean of $157 \mathrm{mmol}(\mathrm{mEq}) /$ day in 24-hour urine samples). ${ }^{5}$ A larger fall (mean $13 / 11 \mathrm{~mm} \mathrm{Hg}$ ) was found in another series ${ }^{6}$ when dietary sodium was reduced to $51 \mathrm{mmol} /$ day without urinary control. Freis ${ }^{7}$ reviewed the epidemiological evidence with some physiological and clinical studies and concluded that reduction of dietary salt to below $34 \mathrm{mmol} /$ day would result in the disappearance of essential hypertension. We believe he is more nearly correct than the Southampton workers, who pay no 